$M P B D B H M G R$ I B D B D L R B F B A F IV,

$H M G R V B F P B D L D B E U B A F V N K F N K R E W S$,

D O NGAUVRNHIFGDNLSERNGM JBNDSAUK $\angle u$

$D \cup$ C Y L I N D E R N D E A C T I V A T I O N S A U K Z Q I N K J 乙

I J GR VCE I OPMNE SWLNCAWZYKFEQLOPNGSA Y B 乙

$N T Z D E Q V M G D N V U S G R V L G R A K G E C L Z E M S A C I T P M O \_$

$L U J G S I R G R E E O M N Y A Z T E F N A X J R \cap N \cap Z M M N D A B O N Y$,

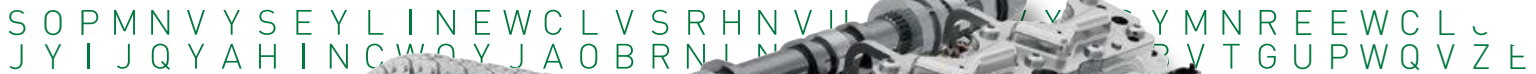
KPELOPMSEB A

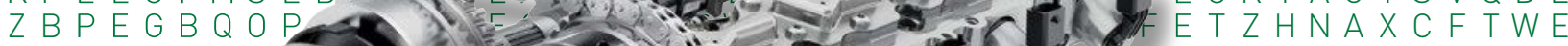
TNEHBNZW A

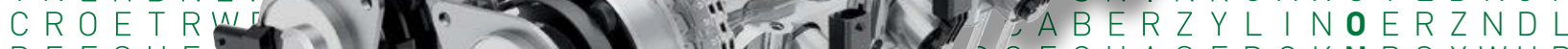

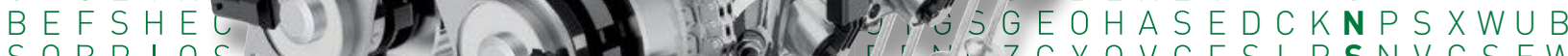
$\mathrm{SOBP}$ O O S . FE I WREQR I U RAR CWDA YWTRDXEXWA $P J M F \mid J H L M O K N$ J $U H B Z G$ C GTVDGLETUOAN J L Y C E P R Z R $J T Z G E T O \mid Z R W Q /$ IJ O M B C I N V X VWMCRWUUMP I ZR AKDPJKPSDFGH J L S E

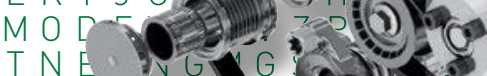

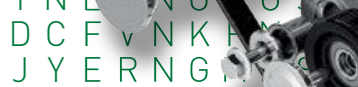

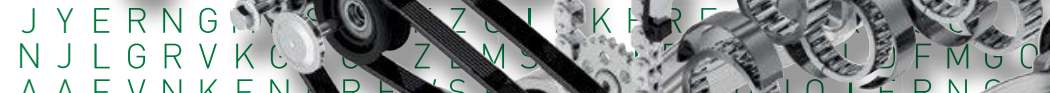

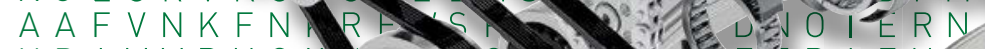
$U D A M M B V C X$ A A MWRZ I R F H W
MODXESNWAS $M O D X E S N W A S$
$U D P S F H K T V N$. FEDGJLKHESY C I MNSTHUZLPQACEZRWDX. HBMWRZIRFSRECVFHKNUTEQQA $P J M N|J| K O O K N \mid J U H B Z G V T F C R D X E S N W A N Z L M O$ I JEUHBZGTF $C G T J D G L E T U O A D G J L Y C B M W R Z$ I PSFHKTVSYSCBFGMHTILQWR $J T Z U E T O I Z R W Q E T U O M B C Y N V X A D G J L K H E S Y S C B F G M H T I L Q N V$ 


\title{
Pure Efficiency
}

\section{Developing combustion engines from the perspective of a supplier}

\author{
Dr. Martin Scheidt
}

Matthias Lang

Dvv

$J \mathrm{ZMH}_{2}$

$A G Q S W \mid\llcorner$

F I M B CHSEH レ

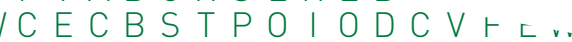

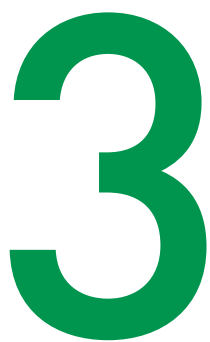

$D G \vee T Q U J X R E L K J H G F D S A \mid v_{1} \ldots$

Y L MRTX A G YWPHCEQA YWS X E E C $\pi$.

CXVNHOUBI JBZGVTFCRDXESNWASK

$Z V T F L U J A D G Y C B M W R Z$ I P S F H K T VNZLMU

$X D B P O R U T E T M B C Y N V X A D G J L K H E S Y S C B M B 乙$

DC SKUP OWRWZTWHNEDKUNWPONCALVIKZTWH N

EHKLPFLKJKO|UZTREWQYXCVBNM | QW O O I U Z T R

WDXAYHASGSVNPIZRWQSCGZN J|MNSTRVNP|ZRWQ_

I L Z U KOGIKCKPMNESWLNCXWZYKFEDIOPPMNESWLNCX

$R \cup C Z G Z M Q G O D N V U S G R \vee L G R \vee K G E C E Z E M D N V U S G R \vee L G h$ QATSLOKZINEXOMNYAZTEWNFX JLRNIFEXOMNYAZTEW

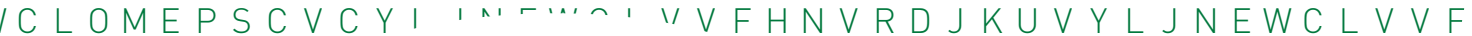
F A MUAN J Y O '

KMN S R D O

LI E P N N

B S A T B

P I E P I

$R \cup C Z$

B S A

D G V

$Y \perp N$

C X

Z V

$X \mathrm{D}$

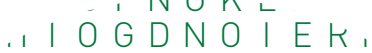

D D L R B E B A F V N n

U A H I O G D O I E R G M

$O Q O D N V \cup S G R V L G R \vee K G$

PDBDDLRBEFBAFVNKFNr

, OTRELKJHGF D S A M B B C X $X A Z Y W P H C E Q A Y W S X E E C R F$ I $O \cup B$ I JBZGVTFCRDXESNWA S U JRDG Y C B MWR Z I P S F H K T V N $R \cup T E T M B C Y N \vee X A D G J L K H E S$ P OWRWZTWHNEDKUNWPONCA $F L K J K O \mid \cup Z T R E W Q Y X C \vee B N M$ HASESVNPIZRWQSCGZNJ|M GIKCKPMNESWLNCXWZYKFF

' A S U S V N P I R W S C G Z N J I'

I KCKPMNESWLNCXWZYKF

$10 X O D N V \cup S G R V L G R V K G$

1. NEXOMNYAZTEWNF.

' CYLJNEWCLVVFH'

$\sqcap N \vee U S G R V L G P$
I ZPMFDRO I DFNGKLDFN. $\varsigma A \cup K Z Q H|O G D N O| E R N$ L REWSPDLRBEFBAFVNK $L K Z Q H|O G D N O| E R N G N$ Z E M D V U S G R V L GR V K 'NSPDLRB EFBAFVNKF $M O L K J H G F D S A M M B V$ B Z P H C Q A YWSXEEC IVBZGVTFCRDXESN 10 Y C B MWR Z I P S F H K

B M B C Y V V X A D J LK K Z TWHNEDKUNWPr 


\section{Efficiency as the primary development objective}

At the end of 2013, the European Union agreed new $\mathrm{CO}_{2}$ limits. As of 2020, these specify fleet emission values of 95 grams of $\mathrm{CO}_{2}$. This figure corresponds to a consumption of approx. $3.6 \mathrm{l} / 100 \mathrm{~km}$ for diesel vehicles and $4.1 \mathrm{l} / 100 \mathrm{~km}$ for gasolineoperated vehicles. These limits will be the most stringent in place anywhere in the world. It is expected that it will only be possible for premium vehicle manufacturers (with a virtually identical mix of vehicles) to achieve this limit value by partially electrifying large and heavy vehicles. The plug-in hybrid drive is set to play a significant role in electrification, as it is favored by applicable legislation.

Despite increasing electrification, engineers across the entire automotive industry will focus on optimizing the combustion engine for many years to come and for a number of reasons. The most important reason is the tremendous growth trajectory that the global automotive industry can expect over the coming years. Increasing prosperity means that the number of newly registered passenger cars and light commercial vehicles will grow to around 105 million units by 2020, which corresponds to a growth of $40 \%$ compared to 2012 [1]. Emerging economies, as well as newly industrialized countries such as
Brazil, Russia, China and India, will see the majority of this growth. However, there are many first-time car buyers in these countries who cannot afford the costs associated with drive electrification. Therefore in these kinds of markets, automotive manufacturers that use efficient combustion engines to shift electrical drive components into heavy vehicles as far as is possible will be especially successful.

The second key reason, this time for the developed markets such as in Europe and the United States, is the expectation of car buyers for standard consumption figures to be approximately achieved in real life. For plug-in hybrids, this is particularly the case if the distances travelled far exceed the electric range and the vehicle must bear the additional weight of the electrical drive components and the battery. For instance, Volkswagen has announced that the plug-in version of the Golf to be introduced in 2014 will be $250 \mathrm{~kg}$ heavier than its comparable gasoline engine version. An efficient combustion engine with a high weight-to-power ratio can help to fulfill the expectations of end customers in this regard.

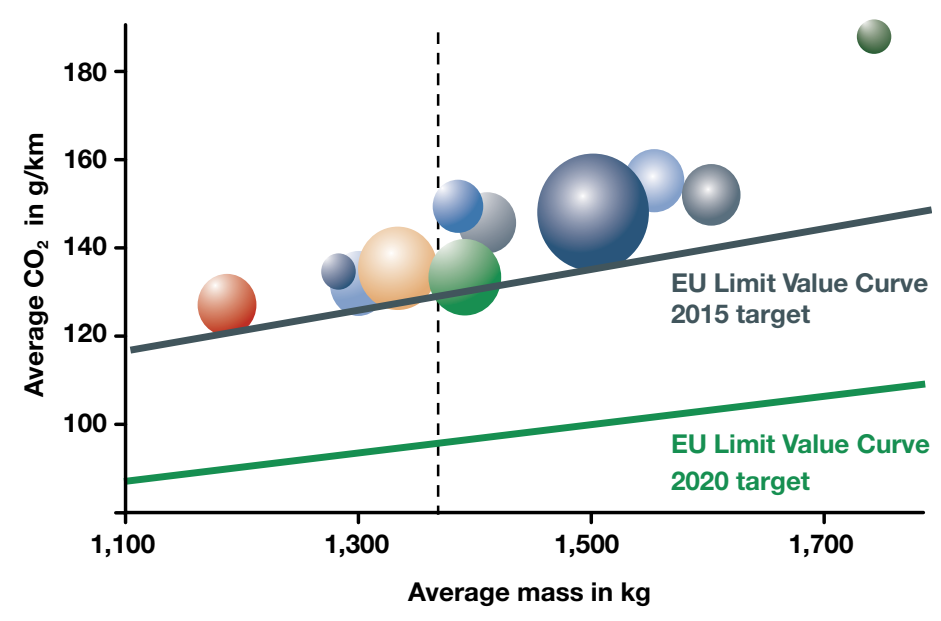

Figure $1 \quad \mathrm{CO}_{2}$ fleet consumption of vehicles sold in the $\mathrm{EU}$ 


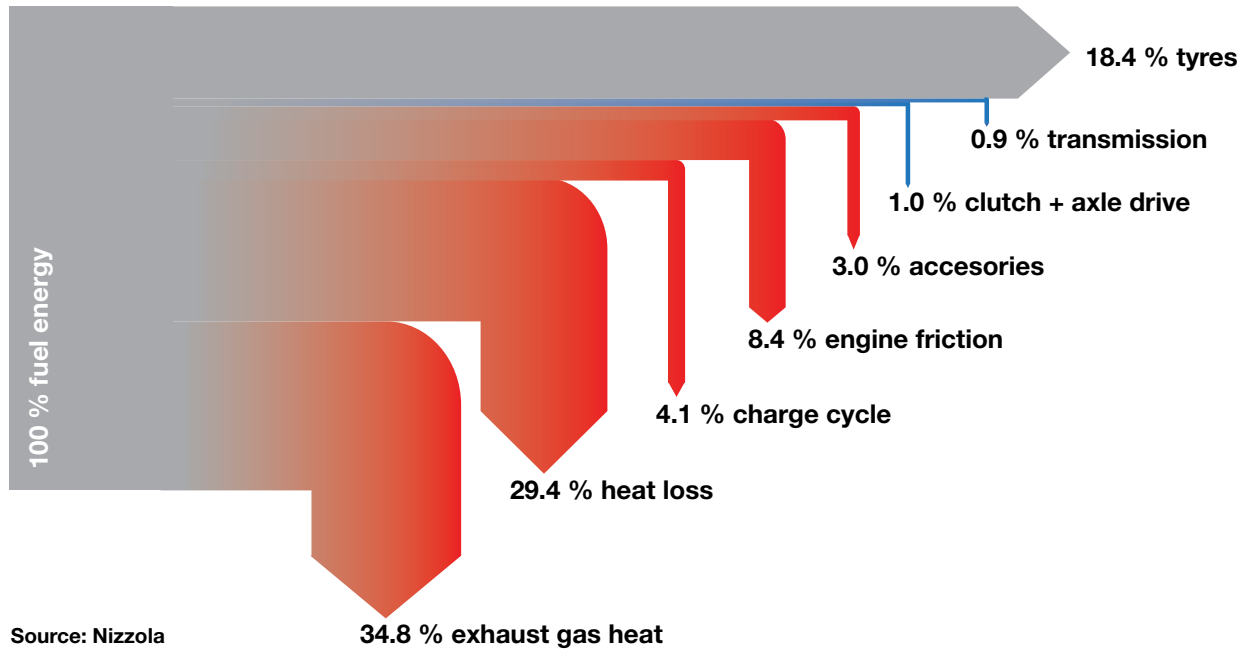

Figure 2 Typical power losses on the efficiency chain from tank to wheel

Finally, it should be noted that the European $\mathrm{CO}_{2}$ limits are particularly strict, but international legislation aiming for similar values has experienced some setbacks (Figure 2 in [2]). From the point of view of a European supplier, there is the possibility of bringing consumption-reducing technologies onto the domestic market at an early stage and thus gaining a competitive advantage on a global scale.

Both EU limit values of $130 \mathrm{~g} \mathrm{CO}_{2} / \mathrm{km}$ for 2015 or $95 \mathrm{~g} \mathrm{CO}_{2} / \mathrm{km}$ relate to a vehicle weight of 1372 kilograms; limit values for vehicles of different weights are calculated using the straight-line method and a weighting factor. As Figure 1 shows, no manufacturer in the EU currently meets the limit value for 2015; the limit values are currently only met by segments of some manufacturers' fleets. In addition, the weighting factor is reduced for the 2020 target, which represents a huge disadvantage for manufacturers of heavier vehicles. On the whole, it is apparent that all manufacturers will need to put great effort into boosting the efficiency of their vehicle fleets.

\section{Approach to improving efficiency}

The efficiency of combustion engines can only be increased if the actual engine comes as close as technically possible to the attainable thermodynamic optimum. Therefore, the engineers' first priority must be to focus on losses that occur in actual engines. Losses for a typical cycle, in which the vehicle's aerodynamics are not taken into account, can be seen in Figure 2.

In modern powertrain concepts, the engine's special operating states also play a vital role when it comes to standard and actual fuel consumption. This applies to transient states, such as increased acceleration. During acceleration, engines with high weight-to-power ratios and low displacement exhibit relatively high deviations from their optimum operating point. One of the reasons for this is "full-load enrichment", which often needs to be applied at relatively low speeds to avoid knocking combustion and protect exhaust components from excessive temperatures. Other operating states that should be considered in particular include engine warm-up after a cold 
start, and more and more frequently situations in which an engine is partially shut down (cylinder deactivation) or even completely stopped (start-stop/coasting).

Furthermore, the efficiency of modern engines must not be detrimental to the engine-out emissions of exhaust pollutants nor should it result in reduced comfort for end customers.

\section{Potential for efficiency enhancement}

There are two ways of minimizing the losses that occur within combustion engines, and they must be initiated simultaneously: first, increase the actual combustion efficiency and, second, minimize losses, especially friction and pumping losses.
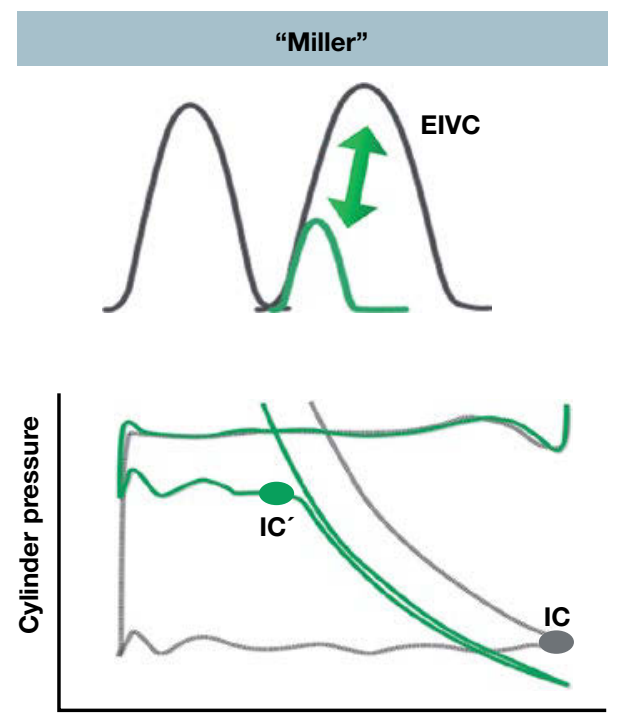

Volume

\section{Reducing pumping losses}

Pumping losses depend heavily on how much the engine must be throttled at a specific operating point. Or put another way: how often can operating points with low throttling, i.e. high load at low speed, actually be achieved through the transmission curves.

The combination of direct injection and exhaust-gas turbo charging to enable this kind of operation has become established on the market. It results in high specific output that can be used for reducing eingine displacement (downsizing). Engines of this type tend to be operated more frequently at dethrottled map points. Cylinder deactivation has a similar effect, also resulting in a higher indicated mean effective pressure in the cylinders still running - and thus resulting in dethrottling.

Extensive dethrottling can be achieved by closing the intake valves early (EIVC) or
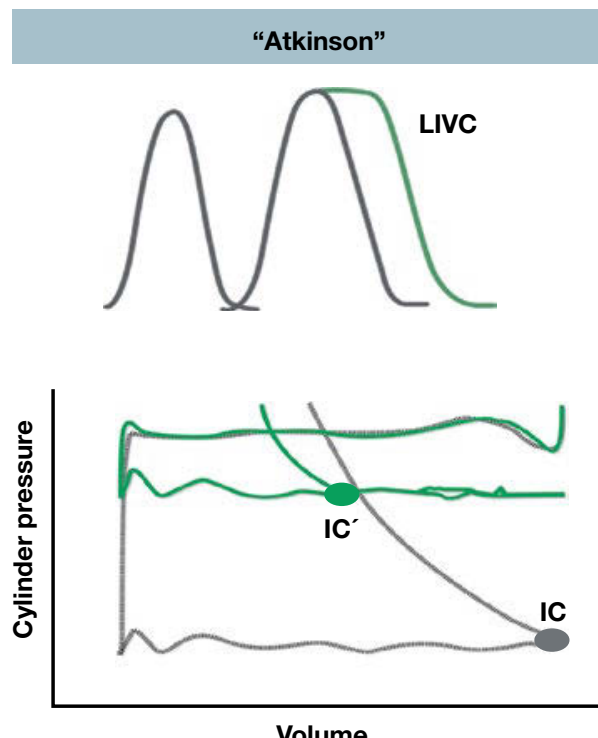

Volume

Figure 3 Dethrottling by changing intake valve timing 


\section{Variable Valve Train}

Valve Timing

\section{Continous}

Hydraulic

Electric
Discrete (switchable)

Two-Step
Electric
Tappet
Pivot Element
Finger Follower
Shifting Cam
Roller Lifter

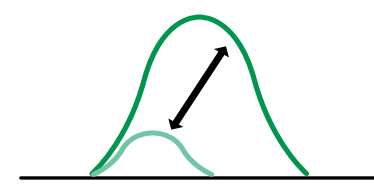

Shifting Cam
Valve Lift

\section{Electro-magnetic}

Mechanical e.g. Valvetronic

Electro-hydraulic

UniAir

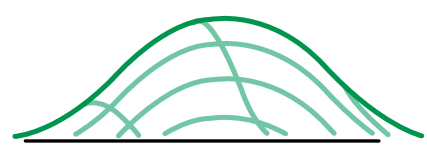

Figure 4 Different types of variability in the valve train

late (LIVC). Both methods reduce the effective compression ratio and are also known as Miller or Atkinson cycles (Figure 3). With the valve opening times thus modified, fourstroke engines experience lower pumping losses but suffer the challenge of reduced combustibility. This effect can be counteracted by increasing the charge motion in the combustion chamber, thereby enabling improved mixture formation and more efficient combustion.

Ideally, to achieve complete dethrottling, it would be possible to freely select the opening and closing times as well as the valve lift for all operating states.

Today camshaft phasers, which only allow partial dethrottling, have already become established on the market. Elements in the valve train for deactivating cylinders continue to be used. The first applications of mechanical and electrohydraulic fully variable valve trains are now available (Figure 4).

\section{Camshaft phase control}

Camshaft phasers are manufactured in large quantities. Hydraulic systems have taken hold, and electromechanical systems are being developed at the same time. The latter provide optimum adjusting speed and variability (Figure 5). However, electromechanical systems are also more costly. With this in mind, Schaeffler is not only working towards the start of production for electromechanical cam phasing systems, planned for 2015; we are also continuously optimizing the performance of hydraulic systems.

The adjusting speed of hydraulic camshaft phasing units is largely determined by the performance of the oil circuit. Engine oil pressure has been consistently lowered over the past few years to reduce the power consumption of engine oil pumps. Low oil pressure is a challenging constraint when it comes to designing new and developing existing camshaft phasers. This is because the lower the oil pressure, the less energy is available to adjust the camshaft. 


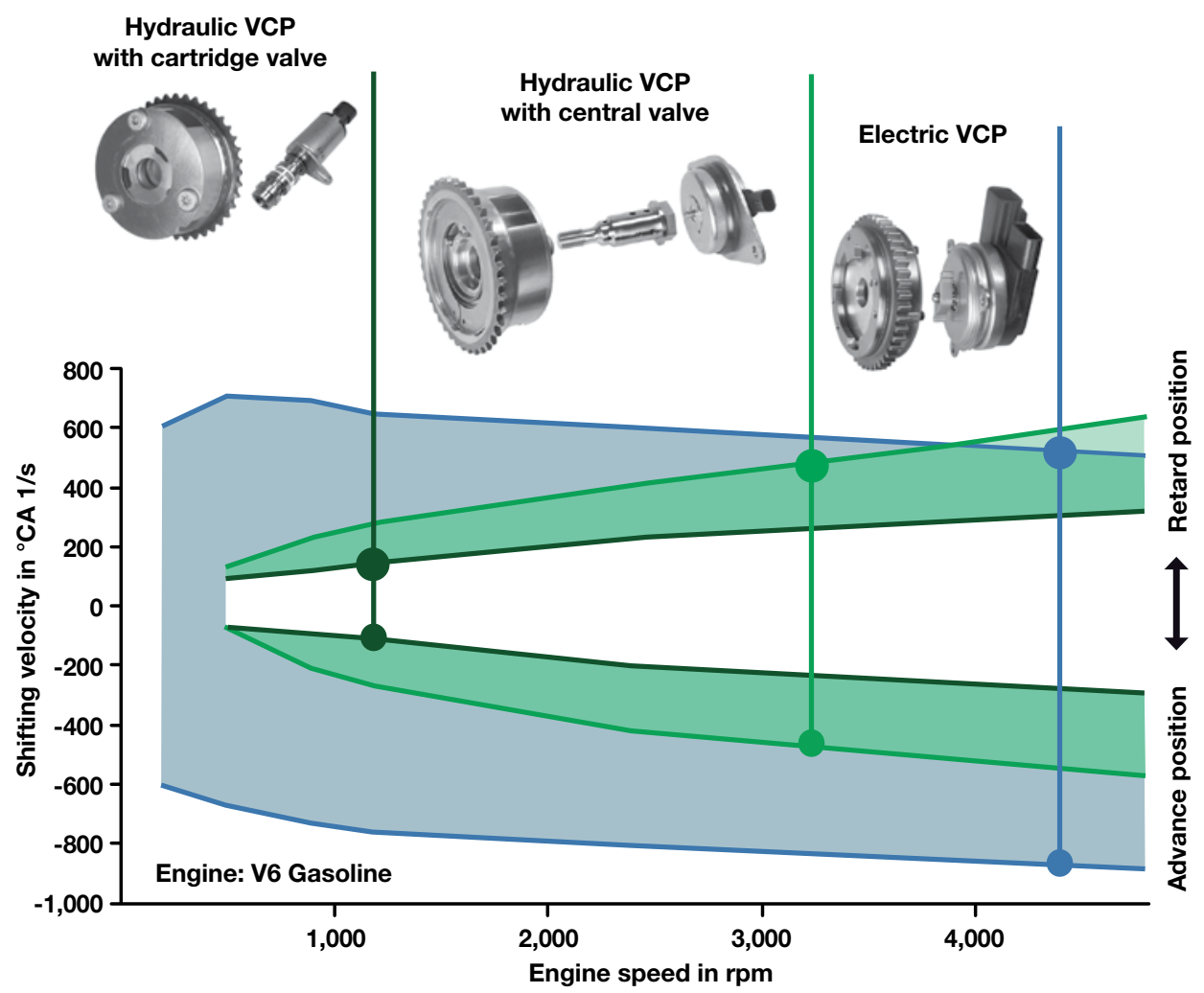

Figure 5 Adjusting speed of hydraulic and electrical camshaft phasers

Schaeffler is therefore showcasing a phaser with a secondary oil reservoir for the first time: the additional oil reservoir is located in additional bores in the camshaft phaser rotor - in other words, right next to the oil chambers that trigger phasing when they are filled. This tank is not pressurized, it improves adjustment speed by providing volume that does not have to be supplied by the oil pump [3].

\section{Switching elements}

Another way to increasing valve train variability is provided by switching elements that vary the lift of individual valves. These kinds of systems are aimed, in particular, at cylinder deactivation, partial dethrottling and internal exhaust gas recirculation, and are available in a range of designs (Figure 6):

- The simplest example merely involves shutting down individual valves - and therefore also the cylinders - via a switched pivot element; these types of elements have been used successfully on the market for several years.

- Switchable finger followers or bucket tappets are also used for two-stage lift switching and therefore for partial dethrottling. By using a sliding cam system, it is even possible to vary the valve stroke in three stages. 3 step cam shifting systems either 
combine cylinder deactivation with switching between two discrete strokes, or allow switching between three strokes. Schaeffler is developing a mechanical solution for 3 step switching, designed to be robust enough to meet all standard requirements regarding valve train service life.

- Using a switchable finger follower, a second valve stroke can be performed outside of the specified first stroke contour. This enables internal exhaust gas recirculation to be performed by either pushing the exhaust gas back into the intake manifold or by re-breathing exhaust gas by opening the exhaust valve a second time during the intake phase. Schaeffler has adapted a system of this kind for a Japanese diesel engine.

\section{Fully variable valve train}

Electromechanical or electrohydraulic fully variable valve train systems offer a high degree of variability, the latter are already in volume production. The electrohydraulic systems are still driven by the camshaft. Electromagnetic systems without a camshaft have been the subject of research for some time, but they have yet to be introduced which is not only attributable to the demanding electrical power requirements. The camshaft also acts as a safety element, preventing faulty actuations and thus the valve and piston coming into contact.

In 2009, Schaeffler started volume production of the UniAir electrohydraulic valve train system. This Schaeffler system includes:

- The electrohydraulic actuator module

- The software required to control valve timing; this software is integrated in the customer's engine control unit

- A calibration data set for the relevant application

Since 2009, this system has been adapted for various production engines with capacities between 0.9 and $2.4 \mathrm{I}$, and delivered in high volumes to customers in Europe and North and South America.

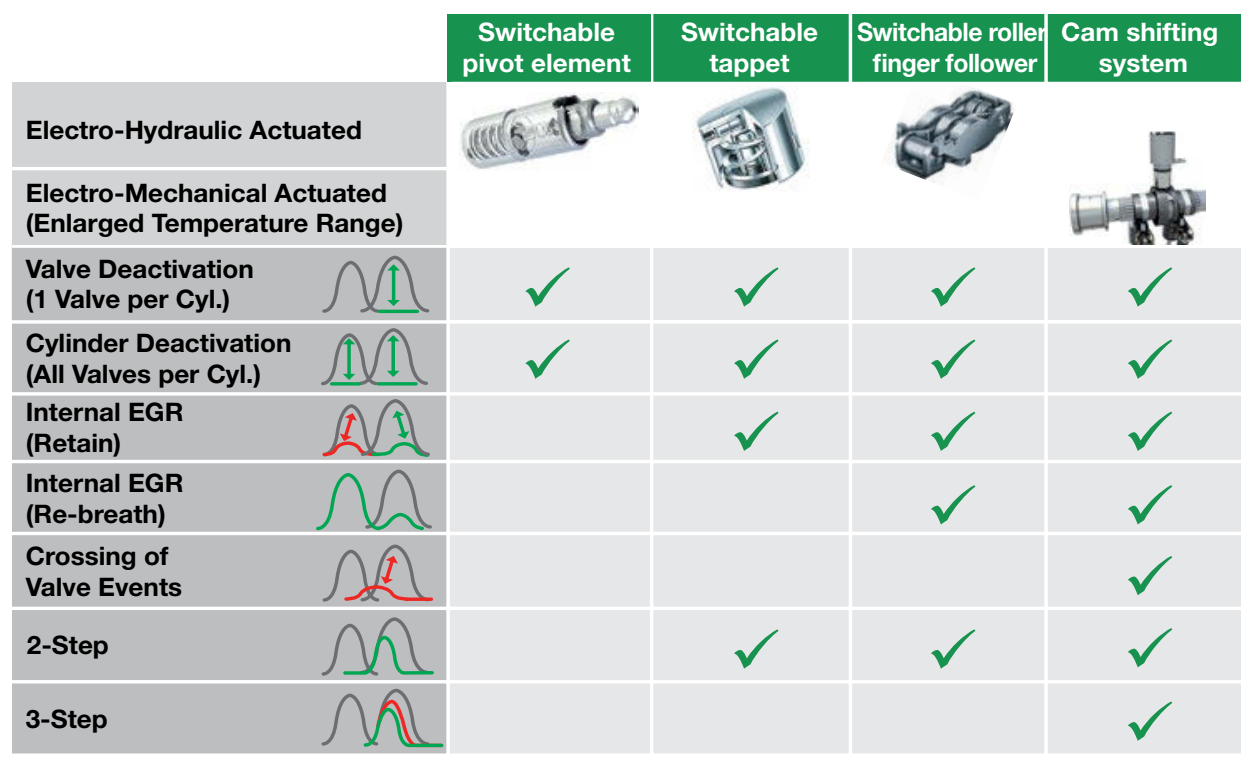

Figure 6 Switching systems for varying valve lift 


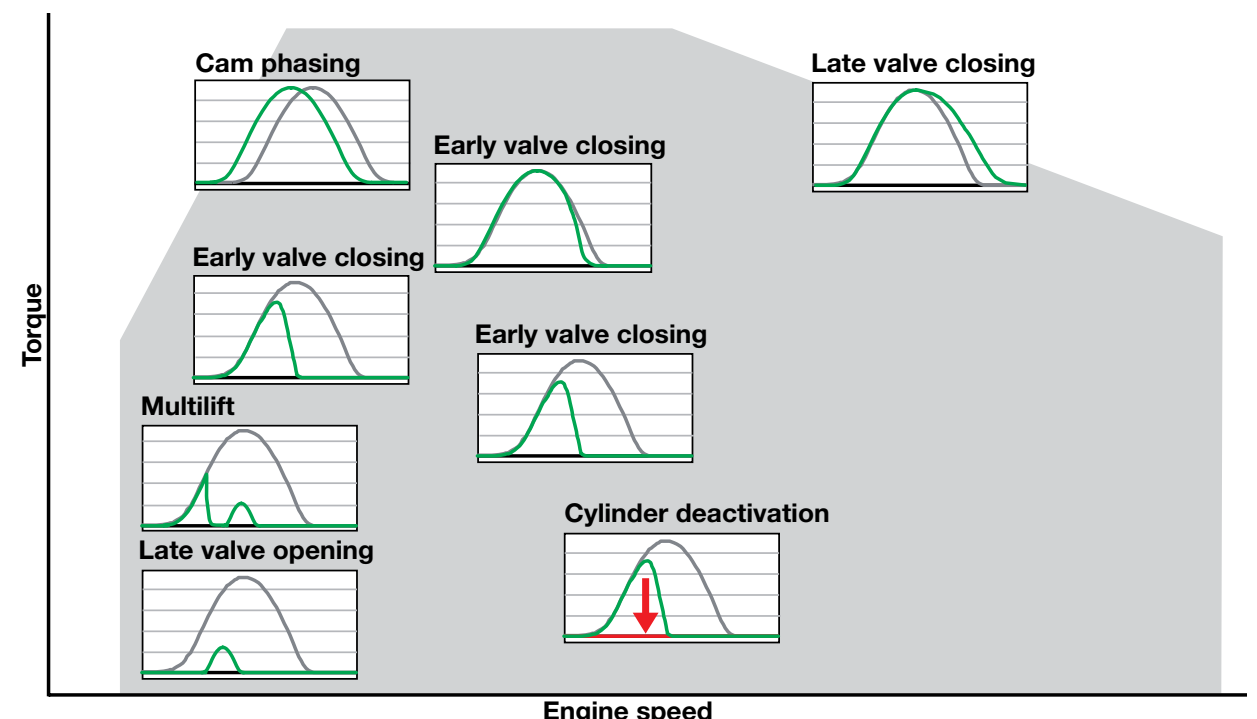

Figure 7 Valve lift curves in different engine map ranges

UniAir not only enables continuously variable setting of the valve lift; it also enables largely free configuration of the valve lift event within the maximum contour specified by the camshaft envelope. In this way, dethrottling is possible within broad engine map ranges (Figure 7). It results in a fuel consumption reduction of up to $15 \%$ in the New European Driving Cycle (NEDC).

Future generations of the UniAir system will feature new functions which will be pre-

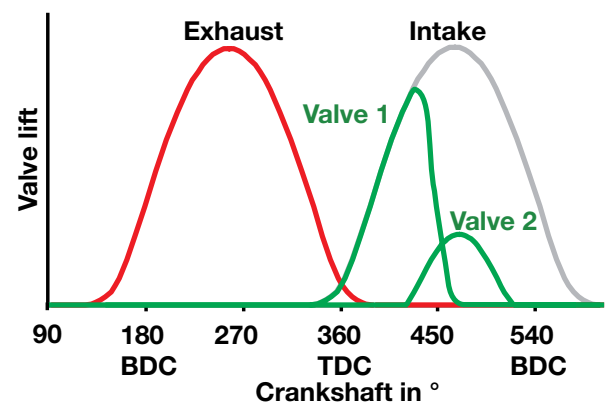

Figure 8 Possible lift curve with individual valve control sented in more detail at the Schaeffler Symposium 2014 [4]. One noteworthy function is individual control of two intake valves. This kind of activation enables a specific charge motion to be generated (especially at low loads), thereby significantly increasing combustion efficiency. Figure 8 shows asymmetric valve lift curves, as enabled by individual control.

From Schaeffler's standpoint, the freedom in combustion process design afforded by the UniAir system can be applied to all vehicle segments. Low-cost engines with a small number of cylinders can benefit from increased torque, while simultaneously lowering specific fuel consumption. In this vehicle segment the cost/benefit ratio is far superior to other measures, such as adding exhaust gas turbo charging and direct injection. Large engines benefit especially from dethrottling in the part load range. New functions can also support future combustion processes that can exploit the benefits of the system's extremely fast actuating mechanism. 


\section{Reducing friction losses}

Reducing friction lossesr has always been a crucial development objective in engine design. In the past, focus was placed on internal friction in the cylinder, particularly friction between the piston/piston ring cylinder pairing. On account of increasingly stringent $\mathrm{CO}_{2}$ legislation, all other sources of loss are now also being studied. This applies in particular to

- Crankshaft

- Valve train

- Balancer shafts

- Camshaft and auxiliary equipment drives

- Losses caused by operating the coolant and the oil pump

In total, these friction values account for about $50 \%$ of the friction losses of an average combustion engine (Figure 9). In addition, the engine heat-up process becomes more important due to the relationship between friction and oil temperature. This power loss has a direct impact on standard

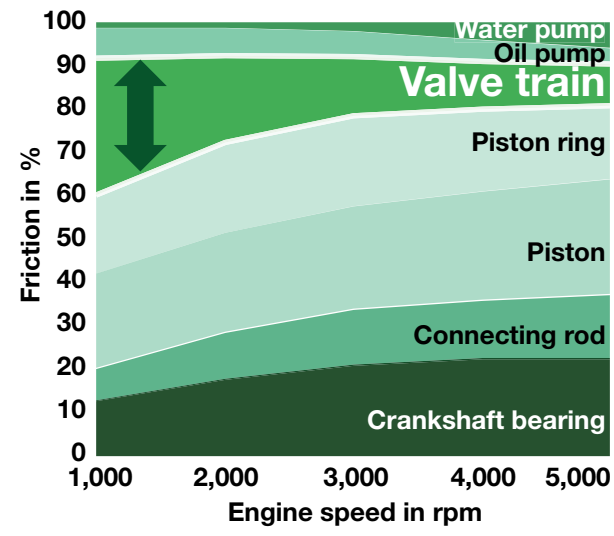

Figure 9 Typical power loss values of individual causes of friction over engine speed for a petrol engine

consumption due to the cold start section in the New European Driving Cycle (NEDC).

The valve train is responsible for a particularly high proportion of friction losses that occurs at low engine speeds. Over the past 20 years, great progress has been made in this area by means of tribological

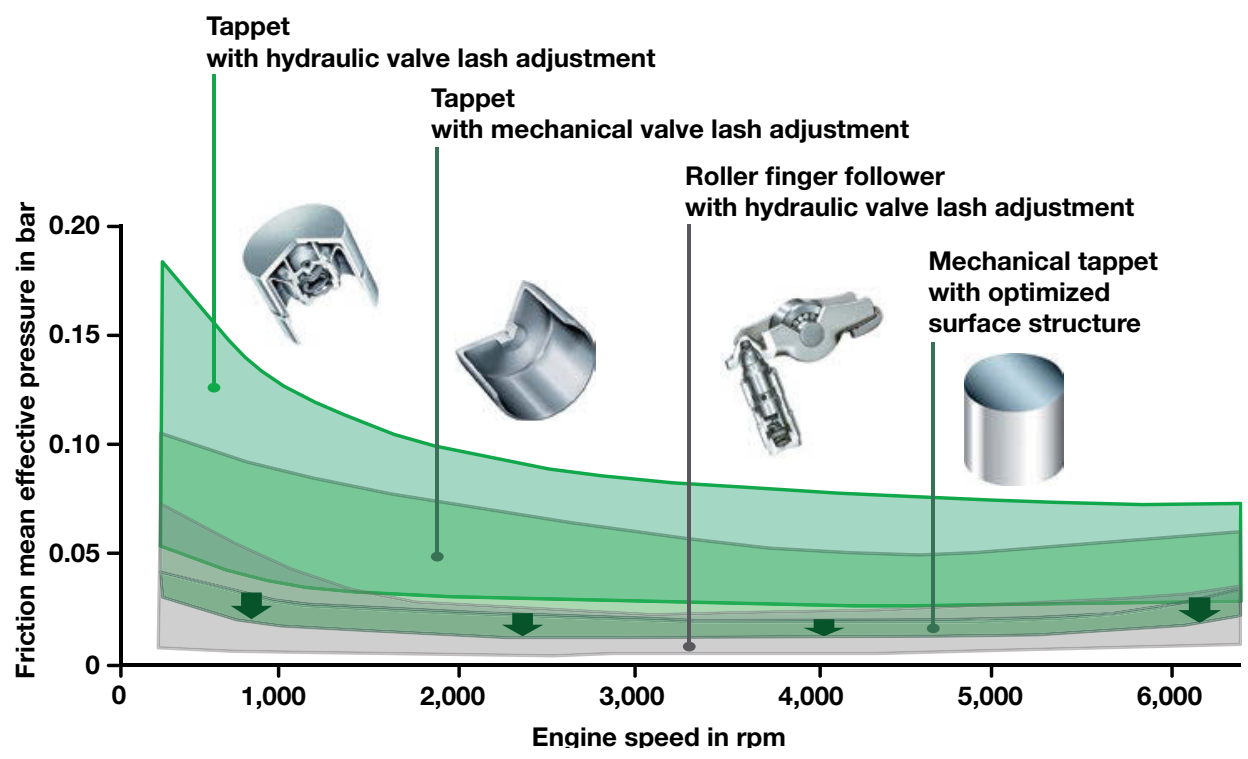

Figure 10 Comparison of frictional power for different valve train types 
optimization of bucket tappets; the friction mean effective pressure has been reduced by around $50 \%$ (Figure 10). At the same time, roller finger followers for valve control have become established - they link hydraulic valve clearance compensators with inherently low friction.

It is increasingly common for modern engines - both gasoline and diesel - with high specific power ratings and few cylinders to be fitted with balance shafts. The friction on the shaft bearing is particularly relevant due to its high speed (double crankshaft speed in a four-cylinder engine). Switching to a roller bearing arrangement while simultaneously designing lighter components (Figure 5 in [2]) can decrease a vehicle's $\mathrm{CO}_{2}$ emissions by up to $2 \%$. In a four-cylinder engine, this kind of solution can reduce the weight by approximately $0.5 \mathrm{~kg}$ per shaft/1 kg per system.

Significantly lower friction losses can also be achieved by supporting the camshaft on roller bearings (Figure 11). However, if this approach is taken, it is essential to consider the assembly concept for the cylinder head.

The key goal for auxiliary equipment drives is ensuring seamless functionality over the service life. Transferring ever-increasing

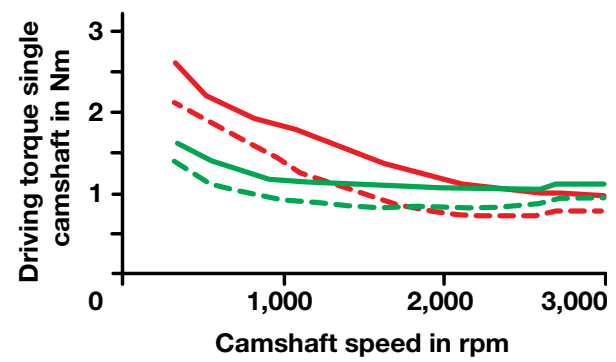

\section{- Plain bearing $60^{\circ} \mathrm{C}$ \\ -- Plain bearing $100{ }^{\circ} \mathrm{C}$ \\ - Rolling bearing $60^{\circ} \mathrm{C}$ \\ -- Rolling bearing $100^{\circ} \mathrm{C}$}

Figure 11 Drive torques for camshafts with plain bearings and roller bearings torques and power ratings results in higher preloads in the belt drive, resulting in increased power loss. At the same time, dynamic amplitudes in the belt drive are increasing as engines have fewer cylinders, and higher mean effective pressures; this results in high rotational irregularities. Innovative belt tensioners and crankshaft decouplers developed by Schaeffler are able to transfer the increased torque reliably while simultaneously minimizing any power loss [5].

\section{More dynamics, fewer losses - special operating states}

Optimizing steady state engine map points alone is not an effective way of improving the overall combustion engine. On the one hand, future consumption test cycles will have higher dynamic content; on the other hand, hybrid systems, in which there is no clear correlation between driving conditions and engine operating points, are being used more commonly.

\section{Acceleration}

The dynamic response characteristic of engines with a high degree of supercharging can be specifically enhanced by setting a positive scavenging gradient. Extremely rapid actuation of the camshaft phaser is desirable to quickly start adjusting the valve timing as required.

Electromechanical phasers allow extremely high adjusting speeds of more than $250{ }^{\circ} \mathrm{KW} / \mathrm{s}$ [6]. They also provide greater rigidity when torque is applied between the drive wheel and camshaft, thereby achieving optimum adjusting accuracy. 
In addition, electric cam phasing is the only option that allows valve timing to be selected as required when starting the engine. By selecting the valve timing, the engine can be started with minimal compression, which results in a low-vibration start and requires considerably less starter power. Electromechanical phasers are largely unaffected by temperature, while hydraulically actuated systems only provide useful adjusting speeds at ambient temperatures of $+7{ }^{\circ} \mathrm{C}$ to $+20{ }^{\circ} \mathrm{C}$, depending on the design.

However, this high performance level goes hand in hand with increased cost. Schaeffler will put this kind of system into volume production for the first time in 2015. The crank angle adjustment range will be up to $95^{\circ}$ in this new system. It is designed to fit to the series engine cylinder head with only small changes.

Furthermore, it is of course important to bring the turbo charger up to maximum speed as quickly as possible when accelerating under a full load. Two-stage turbo charger systems are increasingly being used for this purpose. In these systems, the first supercharger is relatively small and has correspondingly low inertia. The use of rolling bearings for turbo chargers results in significantly lower frictional losses [7] and thus shorter response times. The reduction is so great that the charger could be made larger and yet retain the same response characteristics. For certain engine power ratings, a second turbocharger is therefore no longer required and considerable cost can be avoided.

\section{Engine warm up}

The high thermodynamic efficiency of modern engines also has its disadvantages: significantly less waste heat is produced, which is however needed to heat the engine, transmission and, depending on weather conditions, the vehicle interior. At the same time, the test cycles for determining $\mathrm{CO}_{2}$ and exhaust emissions demand a cold start. To distribute the initial heat produced in an optimum manner, regarding passenger comfort and emissions, Schaeffler has introduced a thermomanagement module (Figure 12).

In the engine warm up phase, the module can completely shut off the coolant entering the engine or set a minimum volume flow. When the engine is at operating temperature, the coolant temperature can be regulated quickly to various temperature levels, depending on load requirements and external conditions. The component has two coupled rotary slide valves that use a single drive. The first volume engine equipped with a Schaeffler multifunctional cooling water controller is the 1.8-I TFSI engine manufactured by Audi (four-cylinder in-line engine, third generation). The module heats up the coolant at a rate that is up to $30 \%$ faster than the predecessor engine which has a wax-type thermostat. In fact, the time required to achieve target oil temperature is reduced by $50 \%$ [8].

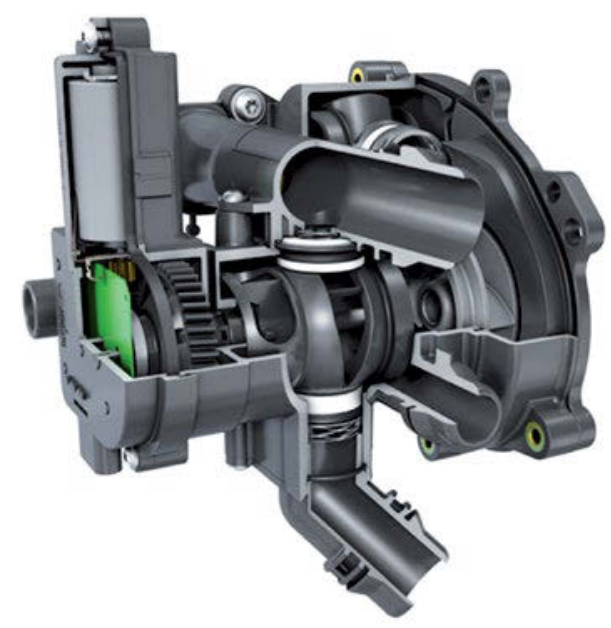

Figure 12 Structure of the Schaeffler thermomanagement module with integrated water pump 
Compact designs for smaller engines and vehicles and further development of functional integration are the focus for future applications [8]. Development includes a multifunctional module with separate circuits for the engine block and cylinder head (split cooling). Schaeffler estimates it is possible to save up to $4 \mathrm{~g}$ of $\mathrm{CO}_{2}$ per kilometer with skilful application of a thermomanagement module. A controllable water pump is a particularly good solution for commercial vehicles whose cooling systems are designed for hill climbs, and thus allow power reduction when driving on level ground.

\section{Engine switch off}

Naturally, an engine has the lowest fuel consumption when it is not in operation, which is why modern vehicles increasingly switch off the engine not only during test cycles but also in real traffic situations. The expectation for 2016 is that two thirds of all new vehicles sold in Europe will feature start/stop systems; from 2019, they will be standard for conventionally powered vehicles in most segments [9]. NEDC consumption can be reduced by up to $4.5 \%$. In the future cycle "Worldwide Harmonized Light Vehicles Test Procedure" (WLTP), the percentage of engine downtime decreases from $23 \%$ to approx. $13 \%$. This means that using start/ stop does not achieve the same level of reduction. However, the WLTP is more dynamic overall, so that vehicle coasting functions gain in importance.

At its simplest, coasting - or better the restart of the engine at the end of the coasting phase -can be achieved using a beltdriven starter generator. The development target is to be able to switch from one operating state to the other with the change being barely perceptible or even imperceptible for the driver. However, compared to conventional belt drives, high torque spikes occur that make new belt tensioner concepts

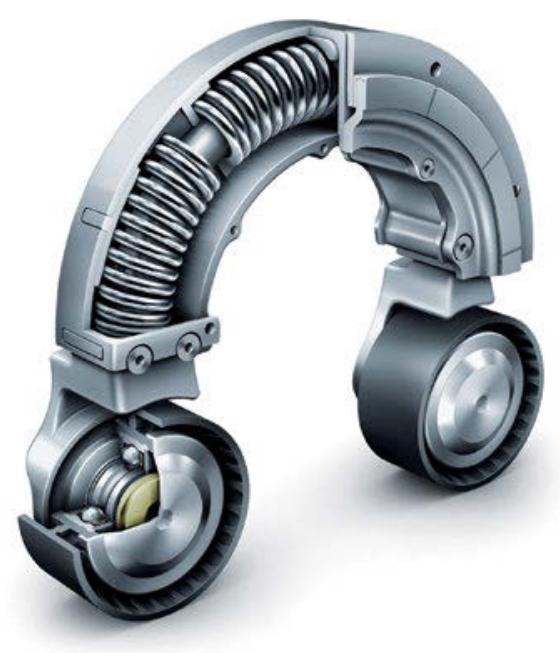

Figure 13 Schaeffler decoupling tensioner

necessary. The wide variety of possible concepts range from using twin mechanical tensioners to a hydraulically actuated tensioner. Schaeffler's preferred option is a decoupling tensioner installed on the generator (Figure 13).

The function of this new tensioner is explained in detail in [5].

\section{Outlook}

Using the technologies outlined in this article, the efficiency of today's already very economical combustion engines can be significantly improved. Schaeffler estimates the entire remaining potential for increasing efficiency of current volume engines to be $20 \%$ for petrol engines and $10 \%$ for diesel engines. However, parts of this potential have already been implemented in engines now appearing on the market.

Furthermore, consistent development of the combustion engine will yield additional potential, even if existing ideas cannot yet 
be covered by technology which is ready for volume production:

- Complete omission of full-load enrichment even on gas-operated engines with a specific output of $100 \mathrm{~kW} / \mathrm{I}$ or more. In addition to fuel savings, this would also reduce engine-out particle emissions

- Replacing plain bearings with roller bearings in the crankshaft drive. The fundamental technical feasibility of this application has already been proven, even if an acoustically satisfactory solution has yet to be found. Studies conducted by Schaeffler have identified potential $\mathrm{CO}_{2}$ savings of around $3 \%$

- Cylinder deactivation that shuts down each cylinder in turn instead of always shutting down the same cylinder [10]; this prevents individual cylinders from cooling down

Schaeffler's viewpoint is that engine and transmission development must be even more closely coordinated in future to fully exploit this potential. After all, efficient drives will only be a success on the market if they meet customer expectations for acoustics and vibration. In turn, the degree by which overall $\mathrm{CO}_{2}$ emissions from road transport can be reduced depends solely on how quickly efficient drives become the norm. The developers of combustion engines and transmissions must overcome this major challenge by working together.

\section{Literature}

[1] Gutzmer, P.; Hosenfeldt, T.: Marktgerechte Reibungsoptimierung. ATZ 115, 2013, no. 11, pp. 876ff.

[2] Gutzmer, P.: Individuality and versatility: future mobility paradigms. 10 $0^{\text {th }}$ Schaeffler Symposium, 2014

[3] Dietz, J.; Busse, M.; Raecklebe, S.: Smart Phasing: Needs-based concepts for camshaft phasing systems. 10 ${ }^{\text {th }}$ Schaeffler Symposium, 2014

[4] Haas, M.; Piecyk, T.: Get Ready for the Combustion Strategies of Tomorrow. $10^{\text {th }}$ Schaeffler Symposium, 2014

[5] Stuffer, A., et al.: Introduction of $48 \mathrm{~V}$ Belt Drive Systems: New tensioner and decoupler solutions for belt-driven mild hybrid systems. $10^{\text {th }}$ Schaeffler Symposium, 2014

[6] Strauß, A., et. al: Quo vadis, hydraulic camshaft phasing unit? 9 $^{\text {th }}$ Schaeffler Symposium, 2010

[7] Kropp, M., et al.: Optimising the transient behaviour of turbo chargers, using the example of a PC diesel engine. $13^{\text {th }}$ International Stuttgart Symposium, 2013

[8] Weiss, M.: Hot and Cold: Schaeffler thermomanagement for up to $4 \% \mathrm{CO}_{2}$ reduction. $10^{\text {th }}$ Schaeffler Symposium, 2014

[9] Kirchner, E.; Eckl, T.: The Long Path from Discomfort to Customer Acceptance - Start-stop systems yesterday, today and tomorrow. $10^{\text {th }}$ Schaeffler Symposium, 2014

[10] Faust, H.: Powertrain Systems of the Future: Engine, transmission and damper systems for downspeeding, downsizing, and cylinder deactivation. 10 ${ }^{\text {th }}$ Schaeffler Symposium, 2014

Open Access. This chapter is distributed under the terms of the Creative Commons Attribution Noncommercial License, which permits any noncommercial use, distribution, and reproduction in any medium, provided the original author(s) and source are credited. 